The magnetic and electrical properties of superconductors were a challenge for many inventors and designers to use superconducting materials in the construction of fully superconducting voltage and current sources commonly called fluxpumps. In the past twenty years a large variety of mechanically or electrically driven devices have been proposed and successfully operated.

In this review the basic principle of operation of each class of devices is shown and specific material problems and limitations are reported. The review will be published in two parts.

Part 1 deals with mechanical devices such as flux compressors and dynamos. Although those devices must have been of great importance for technical application, their construction and operation offered great experience with regard to the properties of superconducting materials, their joint techniques switching and mechanical and magnetic stability under ac and dc conditions.

In this part also a start is made with the more promising class of electrically driven rectifier fluxpumps. With these rectifiers, current levels over $10 \mathrm{kA}$ can be obtained with high efficiency.

In part 2 a theoretical comparison between dynamos and transformer rectifiers will conclude the review.

\title{
Fully superconducting rectifiers and fluxpumps Part 1: Realized methods for pumping flux
}

\author{
L.J.M. van de Klundert and H.H.J. ten Kate
}

\begin{tabular}{|c|c|c|c|c|c|}
\hline \multicolumn{6}{|c|}{ Nomenclature } \\
\hline$B$ & magnetic field & $\mathrm{T}$ & $M$ & mutual inductance of transformer & $\mathrm{H}$ \\
\hline$f$ & frequency & $\mathrm{s}^{-1}$ & $R$ & effective resistance of the normal spot in & \\
\hline$I$ & current & A & & dynamos; resistance of open switch in & \\
\hline$\Delta I$ & current increase & A & & rectifiers & $\Omega$ \\
\hline$I_{\mathrm{L}}$ & load current & A & $\Delta T$ & temperature difference & $\mathrm{K}$ \\
\hline$L$ & self-inductance of the load-coil & $\mathrm{H}$ & $V$ & Voltage & V \\
\hline$l$ & $\begin{array}{l}\text { effective self-inductance of a normal spot } \\
\text { in dynamos; self-inductance of the secondary } \\
\text { branch in rectifiers }\end{array}$ & $\mathrm{H}$ & $\Phi$ & $\begin{array}{l}\text { input flux; } B_{\text {external. }} \text { spot area in dynamos; } \\
2 \hat{I}_{\mathrm{p}} \mathrm{M} \text { in rectifiers }\end{array}$ & $\mathrm{Wb}$ \\
\hline
\end{tabular}

The current carrying capacities of superconducting wires, tapes and cables have improved considerably. Critical currents over $5 \mathrm{kA}$ at $5 \mathrm{~T}$ are now typical design specifications. Applications of these superconductors are now closely related to the heat leak produced by current feed throughs and to the dissipation in the normal parts of the current leads. For laboratory use these losses can sometimes be acceptable, but for technical and commercial operation of superconducting systems, reduction of these losses and as a consequnce high efficiency resulting in smaller cooling systems is inevitable.

One of the solutions to this problem is the flux pump where the necessary energy for the final high dc current is supplied by an acceptable low current ac power supply or by mechanical work. Flux pumps can be used with many

The authors are at the Twente University of Technology, Department of Applied Physics, PO Box 2177500 AE ENSCHEDE The Netherlands. Paper received 30 August 1980. systems, eg, magnet systems for beam bending, levitation, fusion or separation and for high current test beds, energy storage systems or just for the production of high magnetic fields. In relatively small systems the flux pump can be used for the complete loading cycle. In very large systems the flux pump with high efficiency may be a good tool to compensate the inevitable ohmic circuit losses after the magnet has been brought to full current by an external power supply.

The principle of a flux pump ${ }^{3}$ can be understood from Fig. 1. In general, an induction voltage in a loop with series resistance $R$ and self inductance $L$ is given by Farady's Law:

$$
V=\frac{\mathrm{d} \Phi}{\mathrm{d} t}=I R+\frac{\mathrm{d} L I}{\mathrm{~d} t}
$$

If the loop is superconducting $(R=0),(1)$ has the integral:

$$
\Phi+L I=\text { constant }
$$




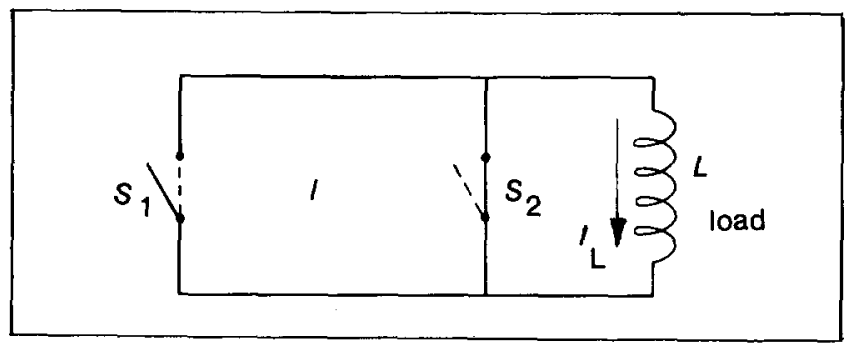

Fig. 1 The basic circuit illustrating the flux pump principle

Here $\Phi$ is some externally applied flux and $L I$ the flux generated by the persistent current $I$.

Flux pumping means changing the value of the constant appropriate for a loop.

Now consider a superconducting coil which can be short circuited by means of two parallel superconducting switches. With switch $S_{2}$ closed for preservation of the already induced current and switch $S_{1}$ open, an amount of flux $\Phi_{0}$ can be added to the pump loop to connect $S_{1}$ and $S_{2}$. By closing $S_{1}$ and opening $S_{2}$, the superconducting current will run in the outer bypass of the coil. The constant is now increased by $\Phi_{0}$. By taking away the flux $\Phi_{0}$ from the pump loop, an increase $\Delta I$ of the current will compensate for this flux loss according to $\Delta I=\Phi_{0} / L$.

This process can be made cyclic by driving away the current from $S_{1}$ to $S_{2}$, by closing $S_{2}$ and opening $S_{1}$. In the absence of energy losses during switching the superconducting current through the coil can accumulate ad infinitum. If we, however, take into account the energy stored in the ignored self inductance of the pump loop it is clear that the current will saturate at $I_{\max }=\Phi_{0} / l$.

From this basic point of view, since $1938^{2}$ a large number of flux pumps have been proposed and built. In this review the modes of operation and the merits of several classes of flux pumps will be discussed. This review is divided into two parts. In part I all basic schemes of flux pumps will be mentioned: flux compressors, dc dynamos and transformer rectifiers. Of these three types the transformer rectifiers actually are the most important.

Part 2 (to be published in next month's issue) proceeds with the transformer rectifier case and reviews the basic theoretical concepts, applicable to both dynamos and rectifiers. Special attention is paid to the power and energy efficiency of these pumps.

Important parts of the rectifiers are the superconducting switches. These will be discussed and an overall evaluation given. The list of references is nearly complete except for the Russian and Japanese literature. The references are arranged according to the subjects and within each subject in chronological order. To maintain the structure and to express the coherence of both parts of this. review, the numbering of the references and figures is continued in part 2.

\section{The flux compressor}

Mechanically operated flux compressors make use of the possibility of trapping high magnetic fields inside superconducting cylinders $\mathrm{s}^{21,23}$ even fields of high homogeneity. ${ }^{24}$ The field strength can be intensified by reducing the area available for the trapped flux. For this purpose a block of superconducting material, eg, $\mathrm{Nb}$ or sintered $\mathrm{Nb}_{3} \mathrm{Sn}$, with two cylindrical holes jointed by a narrow slot is used. The compressor is placed in an external magnetic field parallel to the axes of the holes and cooled down below the critical temperature, typically to $4.2 \mathrm{~K}^{2528,31,32}$ see Fig. 2 . By inserting a superconducting piston into hole $\mathrm{A}$, the flux is expelled there, causing an increase of the flux density inside the other hole $\mathrm{B}$. The final flux density will be

$$
B_{\text {final }}=\frac{\text { area before insertion }}{\text { area after insertion }} \cdot B_{\text {initial }}-B_{\text {losses }}
$$

The $B_{\text {loss }}$ term describes the deviation from the ideal compression ratio. During the insertion of the piston, mechanical work is converted into magnetic energy and stored in the empty part of the compressor. By varying the areas of the holes, any desired compression ratio within the limiting factors of critical density, flux flow dissipation and flux jump phenomena can be obtained.

This flux compressor can be made cyclic if two valves formed by two heaters, which can make the surrounding material normal, are embedded in the walls of the holes (Fig. 3) $)^{22,26,27,29,30,32}$ The compression cycle comprises the following steps:

valve one opens, magnetic flux penetrates into hole $A$ from the external field; valve one closes, valve two opens. By inserting the piston the flux is compressed into hole $\mathbf{B}$. After valve two is closed and the piston withdrawn from hole $\mathrm{A}$ the cycle is repeated. If necessary, the external field can be switched off during the compression phase.

Every cycle, the required mechanical work increases and may set a practical limit to the final flux density. In principle, however, the flux density cannot exceed a saturation value, due to the fact that the flux within the load increases until the field strength within the load (hole B) is equal to that in the compression hole after the compression phase. Furthermore, the compression ratio is decreased because of the increasing flux penetration into the walls of the holes and the piston. ${ }^{25,28}$

The loss mechanisms and the bycoming saturation effect determine the characteristics of the cyclic compressors which are similar to those of the analogues described below ${ }^{26,27}$

$$
\Phi(t)=\Phi_{\text {saturation }} \exp (-p t)
$$

where $p$ is determined by frequency geometrical factor ${ }^{6,7}$ and material properties. Flux compression ratios at 3 to 5 are readily obtained both in single step and in cycle compressors. With an extra iron flux concentrator; a factor of 23.5 has been achieved.$^{27} 2.35 \mathrm{~T}$ is also the highest reported comp-

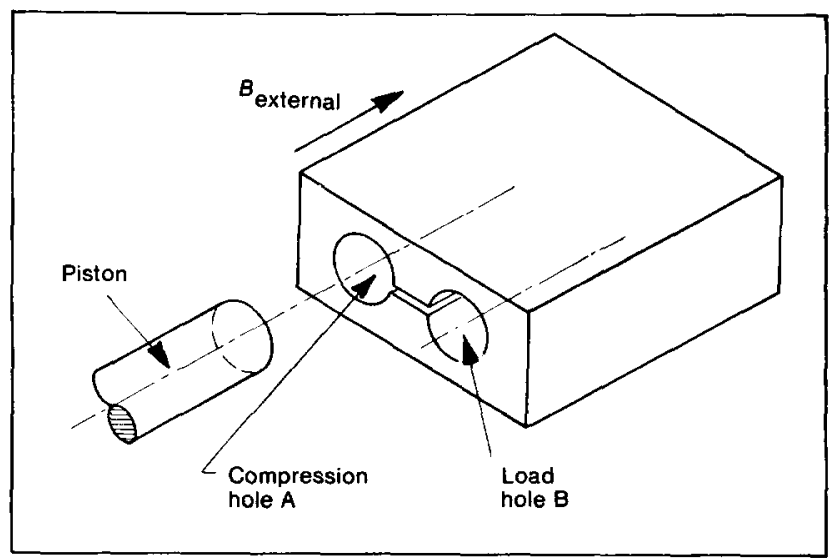

Fig. 2 The single step flux compressor 


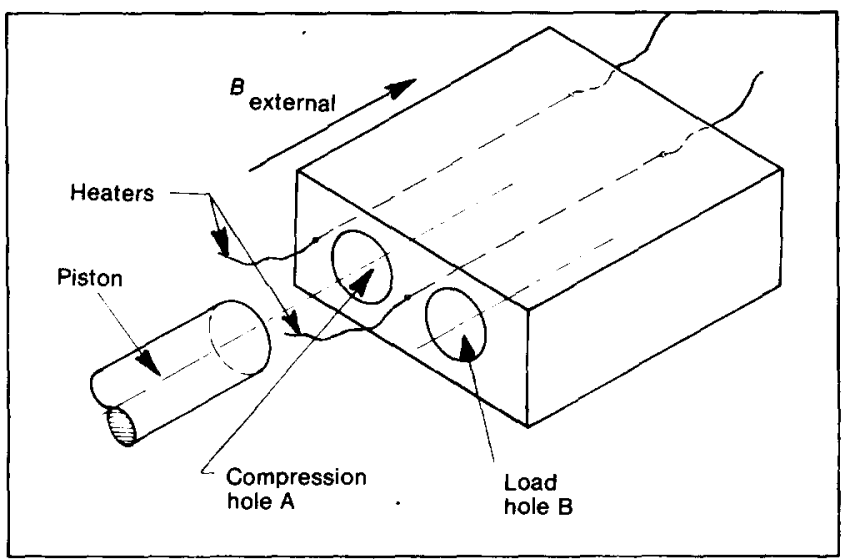

Fig. 3 The cyclic flux compressor

ressed induction, although a field of $5 \mathrm{~T}$ can be trapped directly with some precaution ${ }^{32}$ and shielding of an $8 T$ field has been achieved in $\mathrm{Nb}_{3} \mathrm{Sn}$ cylinders with only one millimeter wall thickness. ${ }^{20}$ The main difficulty is to avoid flux jumps. Probably mechanical friction is responsible for the heat that initiates the flux jumps. Porous sintered $\mathrm{Nb}_{3} \mathrm{Sn}$ with forced helium flow, shows a decreased tendency for flux jumping. ${ }^{32}$ Improvements such as hollow pistons, ${ }^{25}$ premagnetized or tapered pistons, ${ }^{32}$ flux concentrators ${ }^{27,31}$ and soft iron return yokes ${ }^{25,32}$ have been tested.

An ingenious multi step compression device, which avoids the repeated or continuous operation of an external magnetic field, comprises a large tube containing a number of smaller tubes which are premagnetized during cool down to $4.2 \mathrm{~K}$. By taking the tubes out and inserting them inversely one by one with some mechanical apparatus, the flux can be successively compressed (from 63 up to $230 \mathrm{mT}$ with an experimental device ${ }^{33}$ ).

The foregoing provides only discontinuous changes in the trapped flux density. Stepless regulation of a flux compressor is possible if the area of the trapped flux is continously variable. This can be obtained by a set of parallel hollow frames partially covered by a set of parallel plates (Fig. 4). To demonstrate the principle, a device has been built and a maximum of $270 \mathrm{mT}$ was reached starting from an initial field of $70 \mathrm{mT}^{34}$

Moreover it is possible to compress flux between superconductors approaching each other in many configurations.

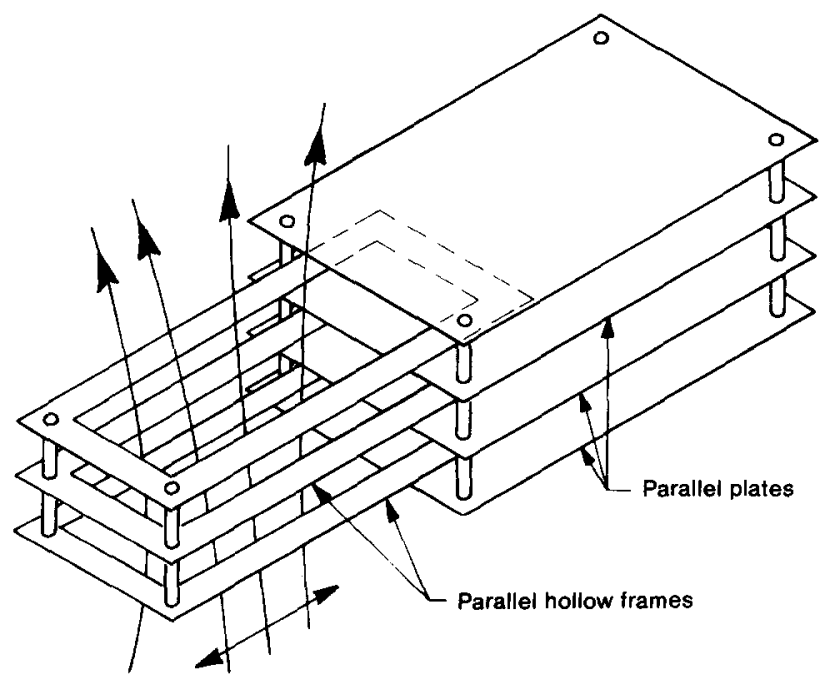

Fig. 4 A stepless regulable flux compressor
Devices with supercond ucting coils in which the magnetic flux increases by increasing the current will be discussed in the following sections. The flux compressors described above produce in reverse operation a magnetic vacuum, typically less than $30 \mu \mathrm{T}$ in an external field of $80 \mathrm{mT} .^{26}$ With special designs a vacuum less than several $\mu \mathrm{T}$ is reached. ${ }^{19}$

Development of the flux compressors can be found in improving the stability against flux jumps. The need for mechanical work within the helium bath is a handicap. The large forces ${ }^{32}$ inside and between various parts are difficult to handle. The discussed failures of these inexpensive and potentially attractive devices prevented their being accepted for general use.

\section{Superconducting de dynamos}

\section{General behaviour}

The main characteristic of this kind of flux pump is the conversion of mechanical energy into electromagnetic energy.

Furthermore the following flux pumps all have in common a superconducting sheet as a 'pumpbridge' connected across a superconducting load coil. The basic idea of these flux pumps is to 'smuggle' flux into a superconducting loop without generating large inductive eddy currents or negative voltages. This flux is then removed 'normally' so that the load current is generated and accumulated every pump cycle again because of flux conservation. A magnet moves from A to B (Fig. 5), and creates a normal region, enclosing the flux $\Phi_{0}$, if the local magnetic field exceeds the critical value of the sheet material. During the passage of the normal spot across the sheet, the superconducting loop shortcircuiting the load coil is not interrupted provided that the spot dimensions are smaller than those of the sheet.

Because the normal spot is surrounded by superconducting material, the induced eddy currents in the normal region are nearly shortcircuited so that only a small negative voltage appears at the edges of the pumpbridge. At point $B$ the flux is removed either by switching off the electromagnet or by moving the magnet away via another path, for example over the leads of a hard superconductor. This causes the great positive induction voltage and therefore the load current increases. Reversing the direction of the magnetic field at point $B$ and moving back to A even doubles this current increase per cycle. The pump cycle may be repeated starting at $A$.

Under ideal conditions for every cycle the trapped flux $\Phi$ increases by the amount of flux $\Phi_{0}$ enclosed by the

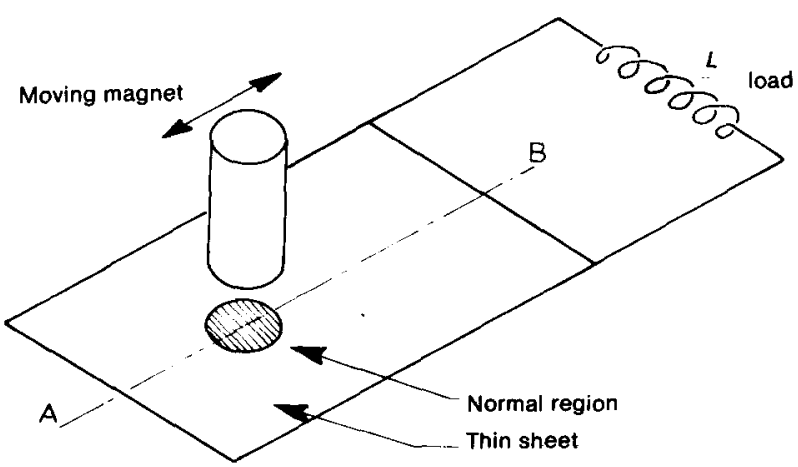

Fig. 5 Simple superconducting dc dynamo 
normal spot. In reality there exist several loss mechanisms around the normal region within the sheet which cause a saturation effect.

The load current and voltage curve of the dynamo, measured by several anuthors, ${ }^{49,51,54,62}$ should follow an ideal expression of the form

$$
\begin{aligned}
& V_{\mathrm{load}}=f \Phi_{0}-2 f I_{\mathrm{load}}-f^{2} \Phi_{0} \frac{l}{R} \\
& I_{\mathrm{load}}=\frac{\Phi_{0}}{2 l} \quad 1-\frac{f l}{R}\left[1-\exp \left(-\frac{2 f l}{L} t\right)\right]
\end{aligned}
$$

The first term in (5) represents the positive induction voltage, the second term the 'switching' voltage drop due to the moving normal spot and the third term represents the voltage drop due to the incomplete shortcircuiting of the induced eddy currents in the normal region. Consequently the second and third term are related to the switching losses and the ohmic losses in the normal spot respectively. The theory will be discussed in detail later.

In the idealized description it is assumed that extra losses are small, partly unknown and difficult to calculate. They are: changes in the sheet inductance of the spot in a magnetic field; spot dimension and local resistivity that vary with spot velocity; ac hysteretic losses within the pumpbridge that vary with current density; hysteretic losses in the permanent magnets and soft iron elements; pinning force retardation of spot motion; temperature increase due to dissipation; decrease of the spot field by screening currents; mutual inductances between local current paths in the sheet; transverse magnetic fields due to eddy currents that distorts the spot field; and mechanical work losses in the liquid helium.

The normal spot moves perpendicularly to the persistent current, disturbs this current distribution and dams up this current to a critical value which gives breakdown switching losses. ${ }^{54,73}$ The measured current distribution in the sheet is not uniform as expected..$^{68,73}$

Several authors studied these problems ${ }^{57,59,62,67,73,80,81,82}$ and analyzed the voltage components during motion. The incomplete understanding of these processes makes it necessary to define effective values $l$ and $R$ for the selfinductance and the resistance of the normal spot respectively. For instance, these values depend on the spot velocity and temperature. Estimates for $l$ and $R$ can be obtained with the help of Maxwell's equations applied to a 'moving normal region' model. ${ }^{82,84}$ Between $l$ and $R$ there is a coupling via the spot dimensions. The nature of this coupling is still unsatisfactorily known. Consequently $l$ and $R$ cannot be varied independently. This makes it very difficult to obtain sufficiently small values of $f l / R$ providing the best efficient operation for this kind of flux pump.

\section{Practical designs}

First we should mention the simple device shown in Fig. $5^{37,54,56,57,68,69,71,73,81}$ which has been built to illustrate the principle and behaviour. For practical reasons an axial geometry has the best advantage and allows for a more compact design.

In Fig. 6 a magnet revolves around the axis of a superconducting disc. A load is connected between the axis and the edge of the disc. ${ }^{36,38,43,46,50,55,62,79}$ In fact,

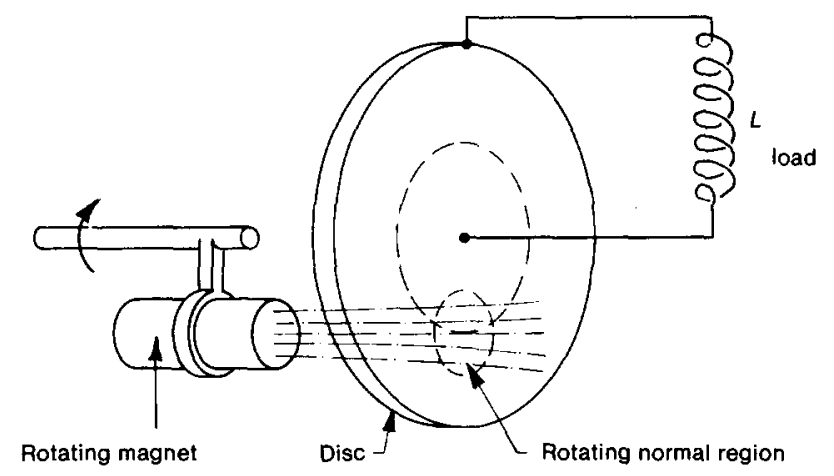

Fig. 6 Simple superconducting de dynamo with axial geometry

this is a superconducting analogue of the good old Ampere dynamo. ${ }^{1}$

Whether the normal spot revolves continuously around the pump-bridge (disc) in the configuration shown, or the normal spot always leaves and reenters the pump bridge as in Fig. 5 is not essential and differs only a factor in the pump losses, which correlates with the time that the spot moves in the pump bridge. We mention two typical models the first one produces $2 \mathrm{kA}$ in a load of $10^{-5} \mathrm{H}$; the second one exists of 48 series connected elementary dynamos mounted on eight decks in a compact construction and drives a load coil of $1.5 \mathrm{H}$ up to $20 \mathrm{~A}$ and a field of $4 \mathrm{~T}$ with a voltage of $50 \mathrm{mV}$ at $20 \mathrm{rev} \mathrm{s}^{-1} .46,50$

The fully superconducting de dynamo differs from the superconducting dc generator which has only superconducting field windings in combination with a normal metal disc. In consequence these superconducting generators are only current generators and not current accumulators, because there is no superconducting current path through the generator. These generators have other problems but they are already in use for heavy currents, high voltages and large power.

Fig. 7 shows a popular geometry. The sheet has the form of a hollow cylinder. $45,60,62,63,64,65,77,78,80,82,84$

The load is connected between the top and bottom edges of the cylinder by many parallel wires divided around the

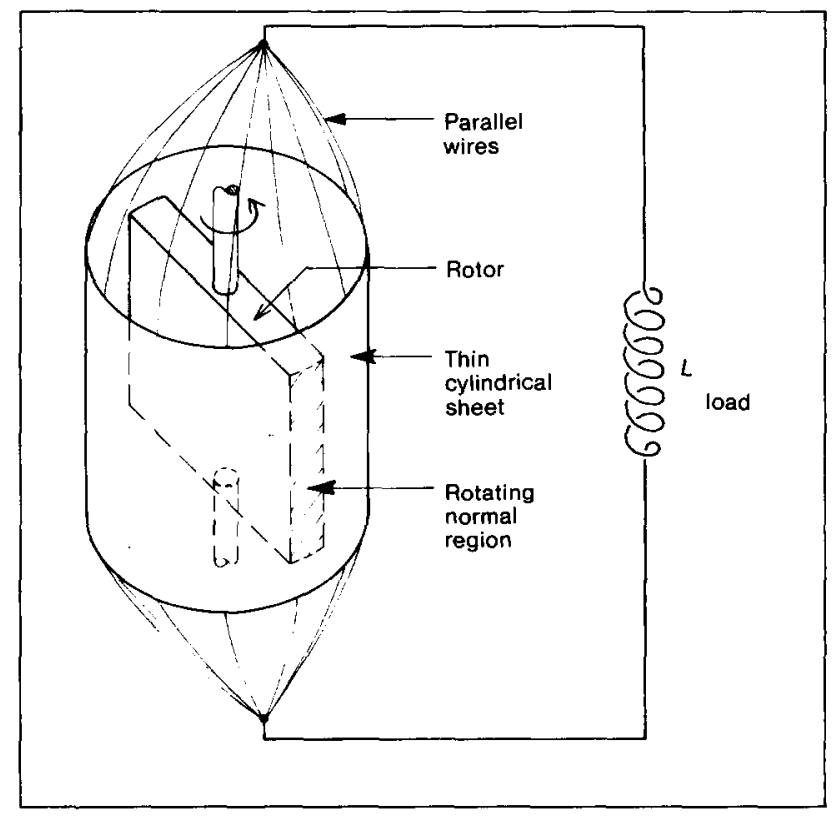

Fig. 7 dc dynamo with cylindrical sheet 
circumference. The rotor consists of one or more magnet poles (permanent or electro magnetic) having the same polarity and creates one or more moving normal regions.

Alternatively the magnets may be fixed mounted around the outside of the cylindrical sheet.

The motion of the normal region is now caused by rotating the cylindrical sheet ${ }^{80}$ or by use of a soft iron rotor which makes a normal spot at its face due to flux concentration. ${ }^{48,61}$

The model of Fig. 7 is used in a design study for a $50 \mathrm{kA}$ flux pump which should work as the current source for a superconducting transmission line test bed. ${ }^{77}$

The $50 \mathrm{kA}$ current has to be reached within 25 minutes at $0.33 \mathrm{rev} \mathrm{s}^{-1}$ within a $20 \mu \mathrm{H}$ self inductance using a 4 poles. rotor. The energy efficiency is calculated to be about $30 \%$.

More devices work in the low kA range ${ }^{6063,67}$ with reported energy efficiencies of 20 to $50 \%$.

In reverse operation the dynamos acts like motors. ${ }^{64}$ Series connections of individual pumps or pumpbridges give higher voltage and power; parallel connections give higher current levels.

For example pumpbridges have been mounted in a circular band ${ }^{83}$ (Fig. 8) or disc ${ }^{40,41,44,46,50,66,71}$ of insulation material of suitable strength. The individual pumpbridges are connected by heavy current leads of a hard superconductor.

A U-shaped pumpbridge placed in the gap between the poles of the yoke of an electro-magnet and the flux concentrating iron rotor allows for a special pump cycle, see Fig. 9. $39,48,59$

When the poles of the rotor move in the face of the pumpbridge foil, two normal regions arise.

The field direction is opposite in both normal spots, but also their direction of motion with respect to the load circuit is in opposition. During the period that the rotor is not facing the pumpbridge the field direction in the rotor is reversed generating the double initial current increase to the load coil.

In 1.0 the next halve tour, the sample is repeated, so that after a complete tour four times the equivalent of the flux in one spot is generated. The apparatus charges a load coil of $167 \mathrm{mH}$ to a field of $3.4 \mathrm{~T}$ at a current level of $56 \mathrm{~A}$ within 130 minutes.

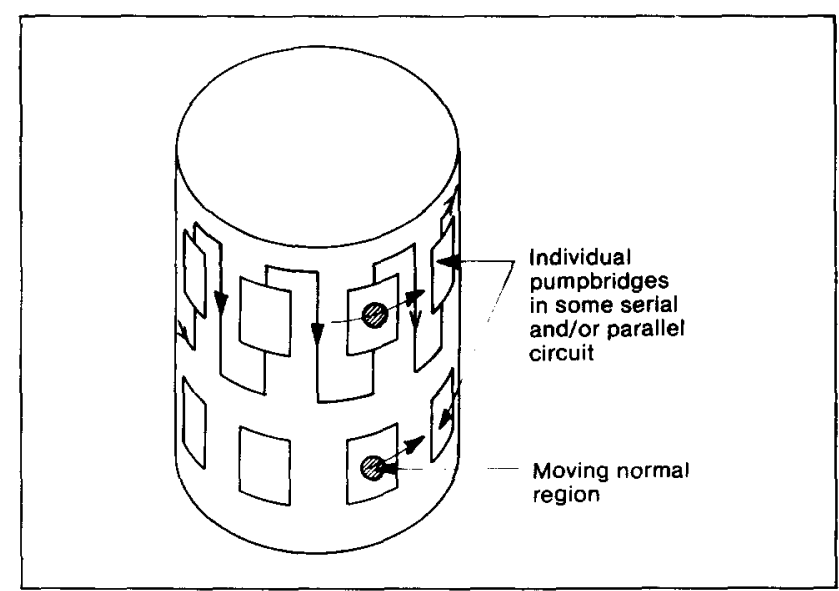

Fig. 8 Some serial or parallel connection of individual pumpbridges in a cylindrical arrangement

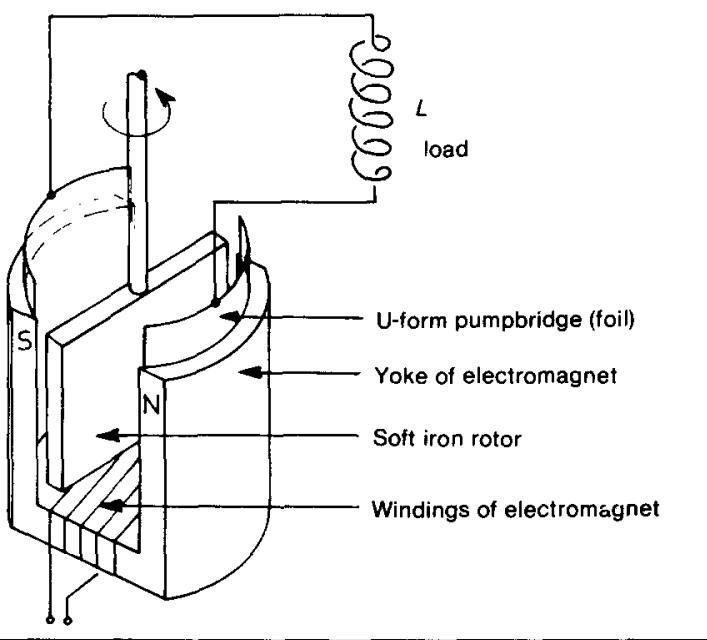

Fig. 9 Rotory dc dynamo-design with U-form pumpbridge

With five foils serial connected, the same coil is charged within 32 minutes. ${ }^{48}$

Other designs charging different coils have been constructed..$^{39,48}$

An alternative without mechanical work and no moving parts is shown in Fig. 10. ${ }^{40,52,66,71,75}$ Three or more phase controlled ac magnets with a dc offset each drive the flux $\Phi_{0}$ into the superconducting loop. This concept allows also an axial geometry analogous to Figs 6,7 and $8 .^{42,47}$ The absence of moving parts would appear to be a great advantage, but that is not true because friction losses due to the mechanical work is negligible for low frequences. On the contrary, the apparatus becomes more complicated and needs a control box.

Two test models reached $85^{42}$ and $17 \mathrm{~A}^{47}$ respectively.

In the apparatus shown in Fig. 11 a temperature gradient created by a heater in the presence of a magnetic field causes flux lines to move across the pumpbridge of a type II superconductor in the mixet state or a type I superconductor in the intermediate state, into the superconducting loop (Nernst Ettingshausen effect). ${ }^{76}$ So far no data have been reported.

In the version shown in Fig. 12, the direction of the moving flux bundles due to the modulation of the magnetic field

Three phase controlled

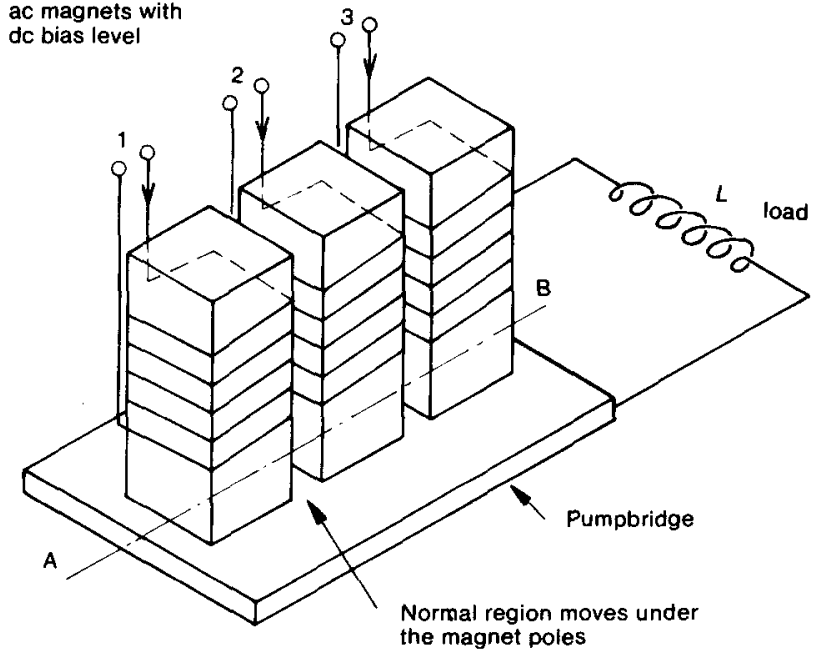

Fig. 10 de dynamo without moving parts 


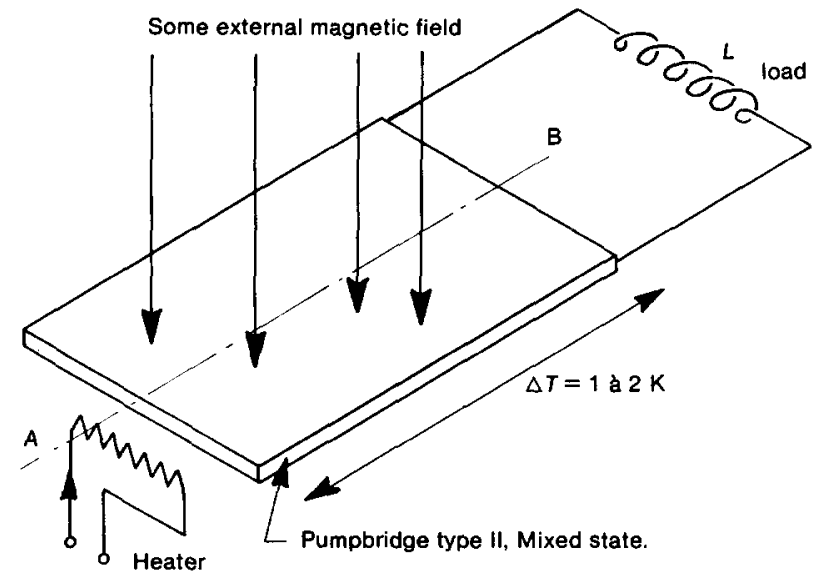

Fig. 11 dc dynamo using the Nernst Ettingshausen effect

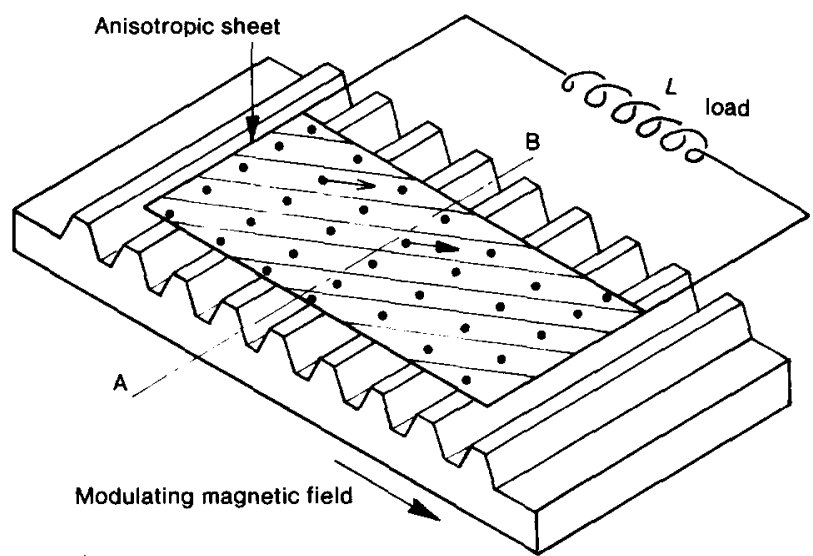

Fig. 12 Guided fluxline motion inside a loop caused by a moving magnetic field

is prescribed by an anisotropy of the material parameters of the sheet. The direction of the fluxlines differs from that of the corrugated magnet pole. A net force on the fluxlines causes them to move inside the loop. The anisotropy is obtained by positioning a set of parallel wires of hard type II superconductors at a small angle with the edge of the sheet. This idea has not been explored in detail. ${ }^{50}$

One of the oldest ideas for fluxpumping is illustrated in Fig. 13, ${ }^{2,66}$

A cross shaped rotor of superconducting material rotates and is in contact with two semi-circular leads via superconducting sliding-contacts. Two rotating arms and the semi-circular leads enclose the flux picked up from an external field and carry it into the load.

Fig. 14 illustrates a similar rotary device. Magnets are mounted in holes made in the cylindrical rotor. The rotor remains in electrical contact with the load via superconducting bearings so that the loop is still superconducting.

Such devices avoid normal regions and the associated loss mechanisms in sheets, but cannot be made trouble free because high current superconducting bearings and sliding contacts are practically impossible to make and are not resistance free.

Therefore the maximum current achieved so far has been only $1 \mathrm{~A}^{58,73}$

In order to avoid the great switching losses associated with moving spots a suggestion has been made to replace the sheet with parallel wires, see Fig. 15. ${ }^{7}$
The electro-magnet only moves across each wire after the current in that wire is inductively made zero. This can be achieved by feeding the measured current in this wire back to a control box for the electromagnet. So the electomagnet gives a negative induction voltage to cancel the current sensed in the wire and then moves past the wire. Consequently, after each cycle the effective pumped flux is reduced and becomes zero when the total initial flux is needed to cancel the current in the inner most wire.

Such a device should work similarly to the inductive commutation mode of operation for the transformer rectifier flux pumps which will be discussed in part 2 .

To our knowledge this design has never been built. With moving spot dynamos, switching losses can be diminished by inductively pushing aside the current at the front of the moving normal region with shading poles. These are extra magnets moun ted just before the pumpmagnet, which reshape the current patterns in the sheet but do not introduce a normal region. The correct position and power of these magnets, however, is dependent upon frequencies and load current so it is difficult to develop an optimum control. ${ }^{77}$

\section{Materials}

The creation of normal spots with simple magnets eventually in combination with soft iron yokes limits the choice of the sheet material for the pumpbridge to relatively low field superconductors with $B_{\mathrm{c} 2} \leqslant 1 \mathrm{~T}$ like $\mathrm{Pb}, \mathrm{Pb}$ alloys, eg, $\mathrm{Pbln}, \mathrm{PbBi}, \mathrm{PbHg}$ or $\mathrm{Nb}$, dilute $\mathrm{Nb}$ alloys, eg,

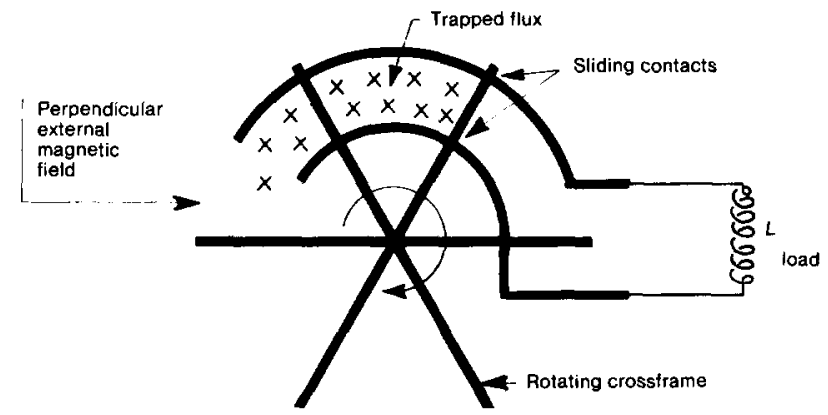

Fig. 13 One of the oldest ideas for fluxpumping, 1938

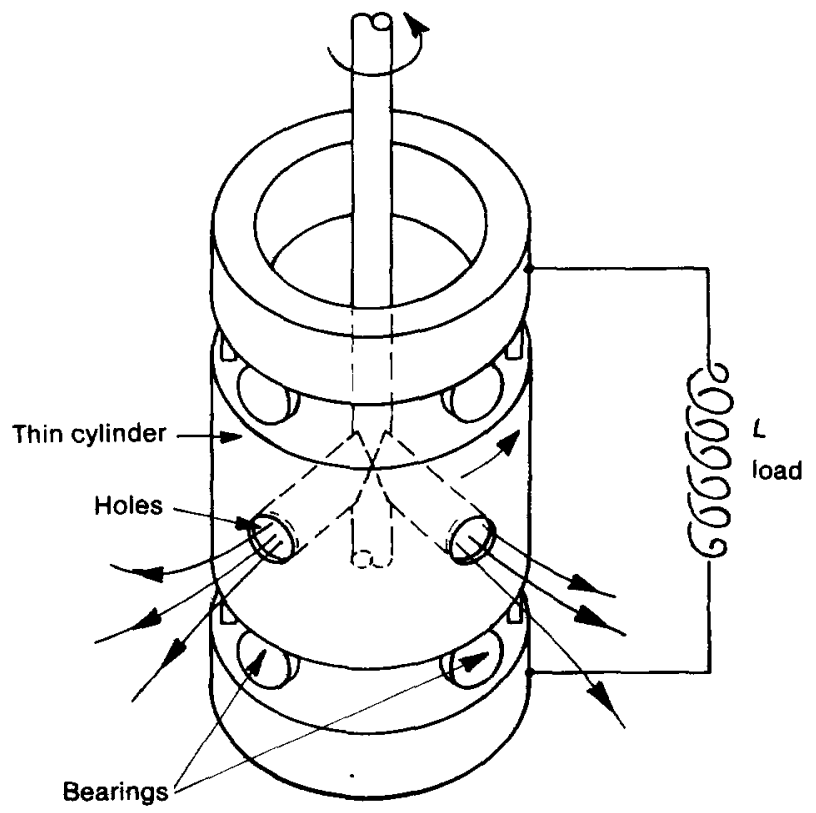

Fig. 14 Dynamo which avoids normal spot losses 


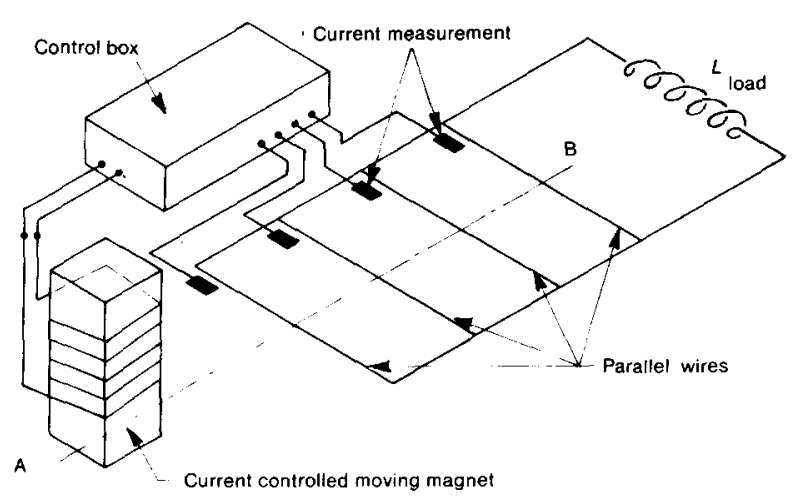

Fig. 15 The composition of the sheet in a set of parallel wires

$\mathrm{NbZr} ; \mathrm{NbTa} ; \mathrm{V} ; \mathrm{Ta}$; etc. The load coil is usually connected to the pumpbridge with many parallel wires to obtain the lowest possible joint resistance and the most uniform load voltage. Current leads can easily be spot welded to $\mathrm{Nb}$ foil or easily be soldered to $\mathrm{Pb}$ foils. The required cross section, which carries the load current, is made by taking a single foil, several layers or a corrugated foil in order to obtain less volume of the device. The thickness must be as small as possible for minimum losses (volume of spot), fluxpinning and best temperature stability. Typically thicknesses are $1 \mu \mathrm{m}$ to $1 \mathrm{~mm}$. Mostly commercial available plate, in the range $10-50 \mu \mathrm{m}$, but sometimes vacuum deposited layers on various substrates are used. ${ }^{38}$ Laminations, slotting or corrugation of the foil give better stability. Generally a good thermal contact to the He bath is required. A thin woven sheet of superconducing ( $\mathrm{Nb}$ alloy) wires (high $\rho_{\mathrm{n}}$ for good pumping) in the current direction and normal copper wires (low $\rho_{n}$ ) perpendicular to the current direction for good stability, has an advantageous area/ volume ratio and may be a significant improvement, ${ }^{77}$ also due to the anisotropy of the material constants. Mechanical stability is needed to withstand the torque which increases with the load current.

The upper limit of the speed or frequency is set by the properties of helium and the friction in the bearings of about $100 \mathrm{rev} \mathrm{s}^{-1}$. In order to limit warming up of the sheet and to avoid great losses $(\sim f)$ it is wise to choose a low frequency in the range 1 to $10 \mathrm{rev} \mathrm{s}^{-1}$.

\section{Transformer rectifier flux pumps}

\section{General behaviour}

In the superconducting dc dynamo-flux pumps, the flux containing the moving normal region acts like a flux source and a 'switch' at the same time. These functions can be separated if one uses another source of flux, like an electrical transformer. Some of the devices so ob tained are essentially superconducting analogues of the well known conventional rectifier circuits. Fig. 16 illustrates this analogy wherein the new circuit consists of a transformer, at least two switches which act like diodes, and a load coil arranged in two loops. These two alternately superconducting loops ensure that the periodically generated current is not dissipated, but accumulated. This is an essential difference with the normal conducting rectifiers.

The use of a superconducting transformer with only a single loop secondary to achieve non cyclic current amplification was proposed in $1933{ }^{85}$ The primary dc current is turned off after cooling down the secondary circuit below the critical temperature thereby generating an amplified dc
9

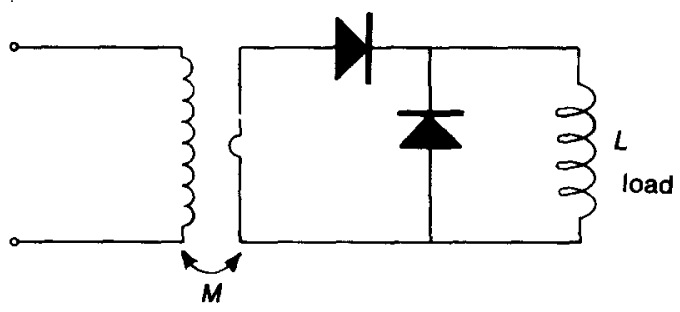

b

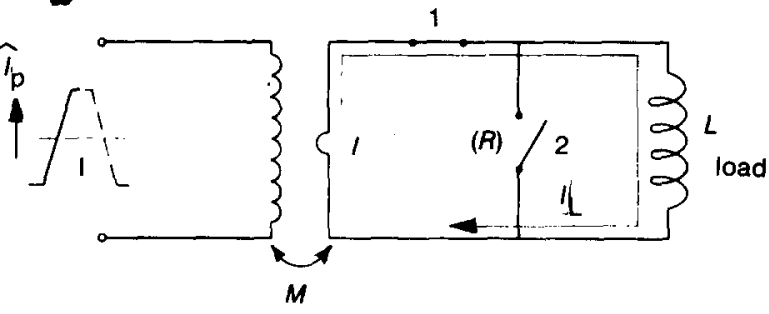

C

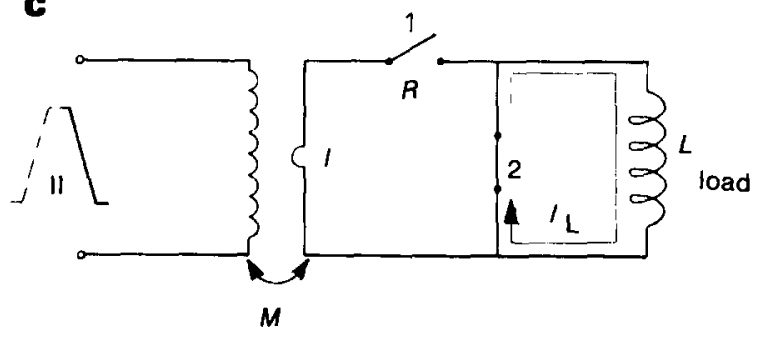

Fig. 16 a - Normal conducting half wave rectifier; $b-$ Superconducting rectifier, pump half cycle; $c$ - Reset half cycle

current in the secondary superconducting circuit in order to satisfy flux conservation. Primary dc current control can regulate the secondary current level ${ }^{88}$

The introduction of two switches in the secondary circuit not only provides cyclic operation but also avoids a limitation on the value of the load coil self inductance for a desired current level.

The actual arrangements of the elements in the secondary circuit yields different types of rectifiers as will be discussed below. The operation of the various rectifiers is explained with the help of a trapezoidal waveform for convenience.

This facilitates the calculations but is not an essential restriction.

\section{Practical designs}

The half wave rectifier-flux pump. A transformer, two switches and a load coil are connected to each other as shown in Fig. 16..$^{90-93,97,101,103,106,108,114,116,127}$

The operation of this rectifier is now described: during half. cycle I the primary trapezoidal current increases, see Fig. 16b. The secondary current also increases because switch 1 is closed and switch 2 is open. Now at constant primary current switch 2 closes and switch 1 opens. The secondary current remains persistent running through the load and switch 2. During the second halfcycle II, the primary current and switches reset to the starting situation successively. For each input cycle only one half is effectively used for pumping. Every cycle the load current $I_{\mathrm{L}}$ increases, but reaches a saturation value after many cycles because of the acting loss mechanisms. These will be discussed below. Detailed information about loadcurrent and losses are described in part 2 . If the desired load- 
current is obtained the load can be set in the persistent mode simply by closing switch 2 , opening switch 1 , and turning off all systems.

Full wave rectifier-flux pump. A full wave rectifier (Fig. 17) consists of a transformer with centre tapped secondary, two switches and a load coil $86,87,89,94,95,96,98$, $102,104,107,111,112,117,118,121-128,130,131$

During the first half cycle 1 , the primary voltage is positive, switch 1 is closed and switch 2 is open. The load current runs in the given direction and increases until the primary current is maximal. Then, at the peak of the primary current, switch 2 closes and switch 1 opens so that the current transfers to the lower loop, but runs in the same direction (II) in the load coil.

As the primary current decreases, the load current $I_{\mathrm{L}}$ increases again (II). In this circuit every half cycle develops a pumping action which thereby doubles the pumping speed compared with the first presented rectifier if all other parameters are the same.

Full wave bridge rectifier-flux pump. A full wave bridge (Greatz) rectifier with an untapped transformer secondary, but with four switches is shown in Fig. 18. ${ }^{104,105,115,118}$ During the first half cycle I, the load current increases and runs via switches 2 and 3. During the second half cycle II, the load current increases again and runs via switches 1 and 4 . Compared with the previous device this design has no practical benefits.

The need for and control of four switches, the open ones in parallel and the closed ones in series, may on the contrary be a disadvantage, but no data are available.

Full wave double load rectifier-flux pump. Two uncoupled load coils can be fed at the same time from one source (Fig. 19). ${ }^{109,115}$

During half cycle $I$ the load current $I_{\mathrm{L}_{1}}$ increases and runs through coil $L_{1}$ and switch 2 .

During the next half cycle II, the load current $I_{\mathrm{L}_{2}}$ increases and runs through coil $L_{2}$ and switch 1.

Each half cycle therefore successively increases load currents $I_{\mathrm{L}_{1}}$ and $I_{\mathrm{L}_{2}}$. During half cycle I, coil $L_{2}$ is shortcircuited by switch 2 .
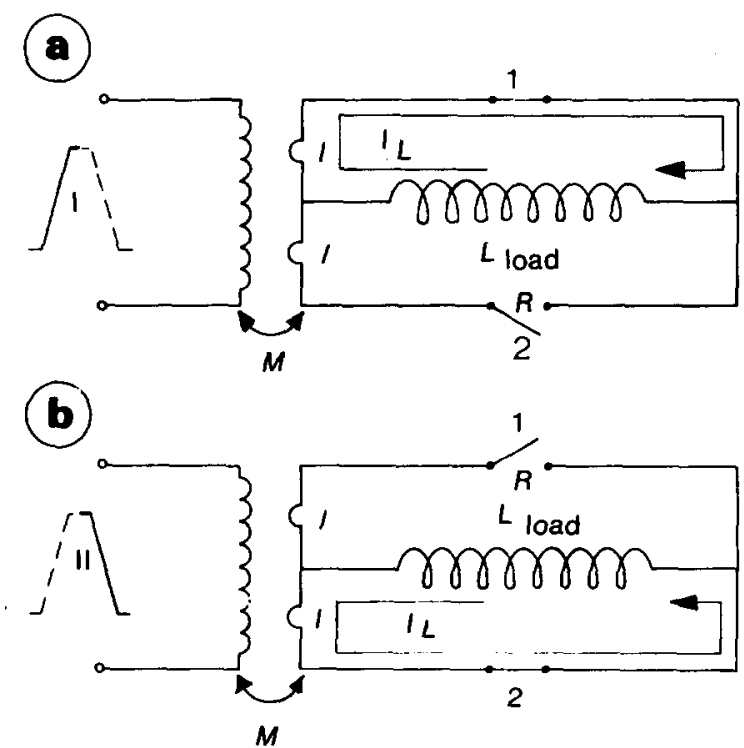

Fig. 17 Full wave rectifier. a - first half cycle; b - second half cycle

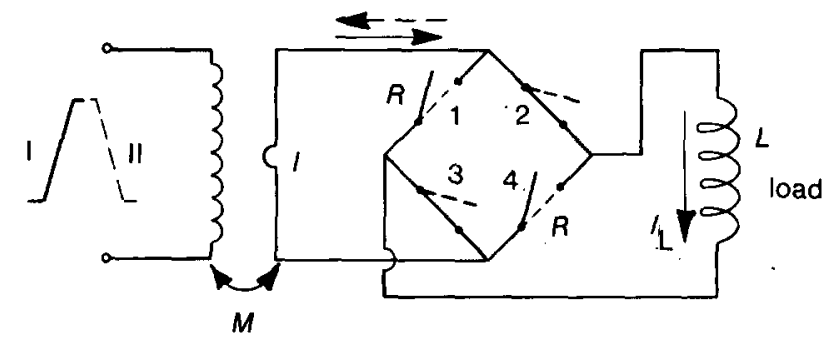

Fig. 18 Full wave bridge rectifier

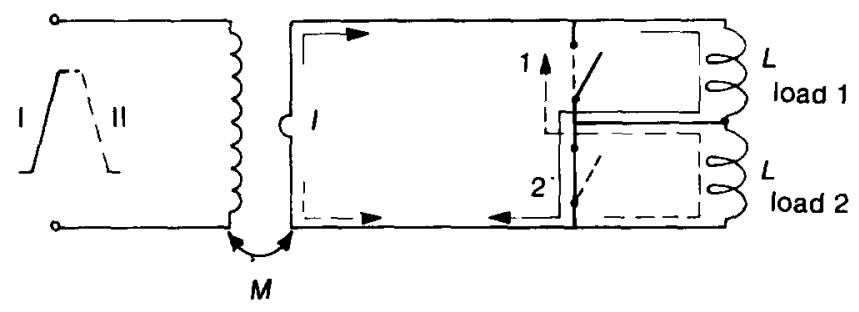

Fig. 19 Full wave double load rectifier

This loop remains superconducting and unbroken so that the concerning load current $I_{L_{2}}$ is unaffected. The same holds for load current $I_{\mathrm{L}_{1}}$ during half cycle II.

Full wave double transformer rectifier-flux pump. Two separate and oppositely connected transformers makes possible the design shown in Fig. 20.115

During half cycle $I, I_{\mathrm{L}}$ runs through the load via switch 2 and the first transformer secondary; the second transformer is shortcircuited by switch 2 .

During the next half cycle II, $I_{\mathrm{L}}$ runs through the load via switch 1 and the second transformer secondary; the first transformer is secondary shortcircuited by switch 1 .

This design works only with switches because the current must be able to run in each switch in both directions. There exists no normal conducting analogue of this rectifier with diodes.

Half wave automatic switching flux pump. A circuit with two parallel unequal superconducting coils has rectifying properties under certain conditions.

A primary current $I_{\mathrm{p}}$, with a special waveform generates a secondary current $I_{\mathrm{s}}$ which drives switch coil $L_{2}\left(L_{2} \ll L_{1}\right)$ normal ( $R$ ) and thereby increases the current linking the $L_{1}-L_{2}$ loop (Fig. 21). ${ }^{99,100,108,110,119}$

When $I_{\mathrm{p}}$ stops rising, $I_{\mathrm{s}}$ falls quickly to zero allowing $L_{2}$ to become superconducting again, leaving a persistent current $I_{\mathrm{L}_{1}}$ into loop $L_{1}-L_{2} . I_{\mathrm{p}}$ is now programmed to fall slowly so as not to drive $L_{2}$ normal. With each cycle $L_{2}$ becomes normal at higher current levels. The remaining load current $I_{\mathrm{L}_{1}}$ increases with $\Delta I$ every pump cycle until the maximum current is reached. For good operation the primary current waveform is unsymmetrical, ie with a much larger slope during the rising than during the falling portion. ${ }^{99,100,108,110}$

Otherwise a magnetic bias field is used for switch coil $L_{2}$ such that its critical current is smaller in the forward than in the backward direction. ${ }^{119}$ Replacing the 'switch coil' $L_{2}$ by a controlled superconducting switch $\left(L_{2}=0\right)$ makes the device non automatic and a defective reading of the half wave rectifier flux pump of Fig. 16.

The continuous dissipation at high current levels in the normal resistance $R_{0}$ and $R$ makes the device inefficient.

A mathematical model is available. ${ }^{119}$ 


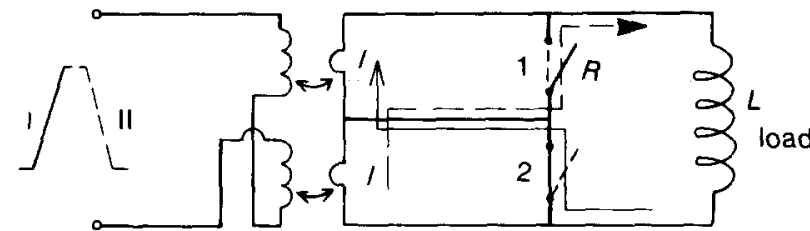

Fig. 20 Full wave double transformer rectifier
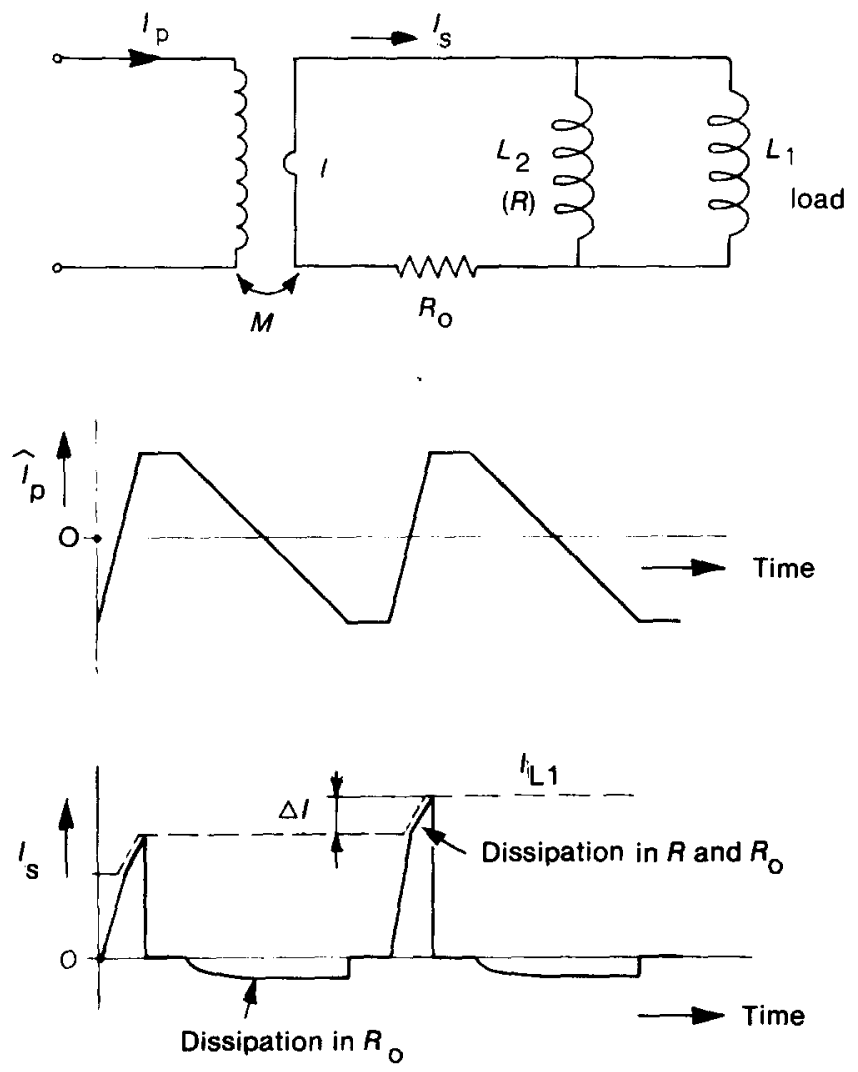

Fig. 21 Half wave automatic switching flux pump

Multi-phase system. In addition to the single-phase rectifier-flux pump arrangements described before, the construction of multi-phase flux pumps is possible according to the multi phase normal conducting rectifiers like the three-phase three-pulse, six-pulse bridge, six-pulse interphase or twelve-pulse rectifier systems. These systems require more parallel operating switches. Three authors mention the nossibility of three phase rectifiers as flux pumps. ${ }^{85} \mathrm{~b}, 104,113$ Parallel operating switches in multiphase systems could be an alternative to high current switches because each switch has to carry only a part of the total load current. Unequal current sharing may become a problem however,

Probably, parallel operation of complete flux pump modules or parallel operation of more switches in the foregoing rectifiers will be more attractive.

\section{Miscellaneous rectifiers}

In the previous section only flux pumps fed from a transformer were treated. Hence the source for the secondary voltages is a time dependent primary current. If, on the contrary, the primary field is generated by a dc coil or a permanent magnet while the secondary enclosed flux is periodically changed, currents are also induced, which can be accumulated in a load coil. So far three methods have been suggested, all making use of the half wave rectifier scheme (see Fig. 1).
In the first one (Fig. 22) a superconducting piston is inserted in the secondary (compression) coil in the presence of a constant external field. ${ }^{21,30}$

This device is the electric analogue of the cyclic flux compressor already discussed.

In the second, see Fig. 23, the area of the secondary loop is varied directly with the help of an eccentrically driven connecting rod. The sketch is the original one of Felici in $1938^{2}$ and illustrates one of the oldest principles of flux pumping. The author proposed thermal heaters then. In both of these configurations again mechanical work is converted into magnetic energy.

The third method (Fig. 24) makes use of the Meissner effect in a type I superconductor. By alternately heating and cooling a superconducting core of the secondary coil beyond its critical temperature for the applied field, flux changes are effected. ${ }^{4,16}$ The efficiency of this thermal magnetic heat converter, however, is very poor.

It may be mentioned in this context that a load coil also can be directly energized by a thermo couple. In principle the hot end of the thermo element can be inside ${ }^{15,17}$ or outside $^{14}$ the cryostat. The coil of course can be used in the persistent mode by means of a persistent current switch. The large heat production or heat leaks seems to make them disadvantageous. As mentioned before, thermomagnetic power generation is also possible..$^{13,76}$

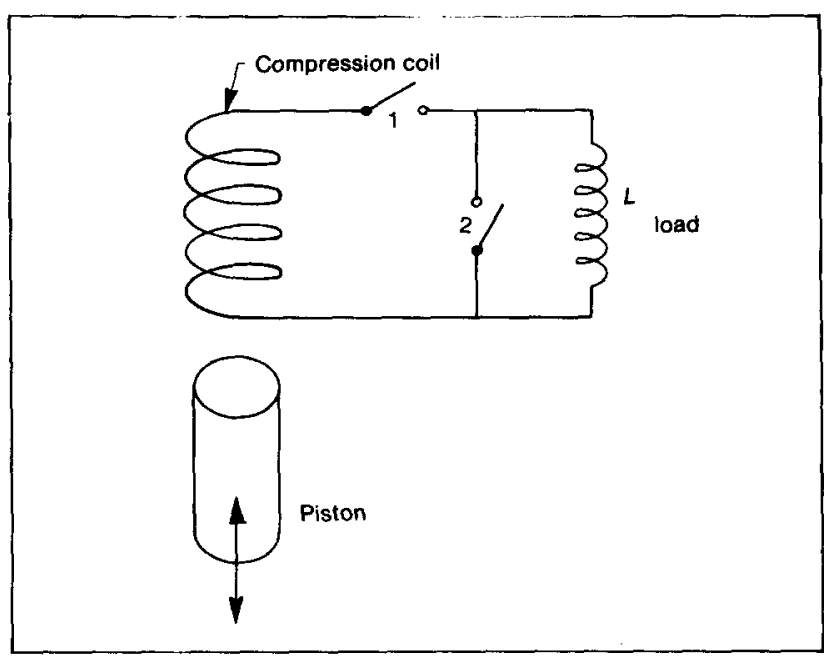

Fig. 22 The electric analogue of the flux compressor

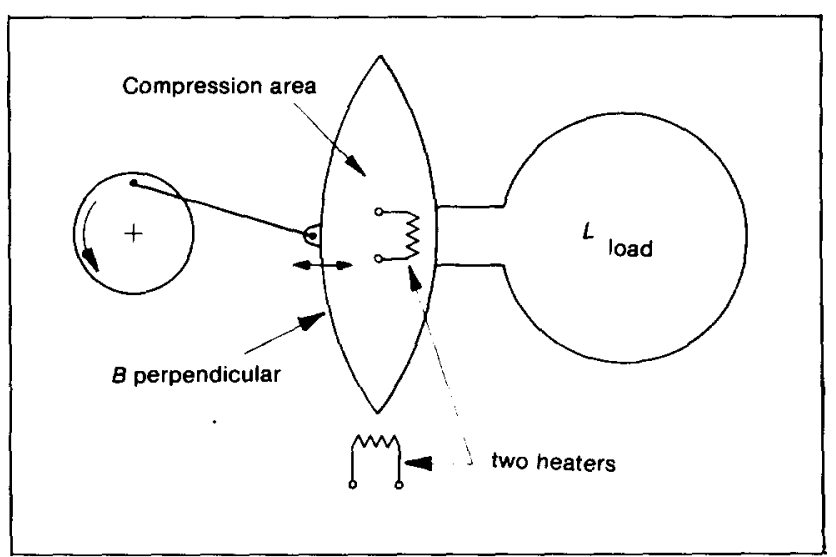

Fig. 23 Mechanical driven half wave rectifier by Felici, 1938 


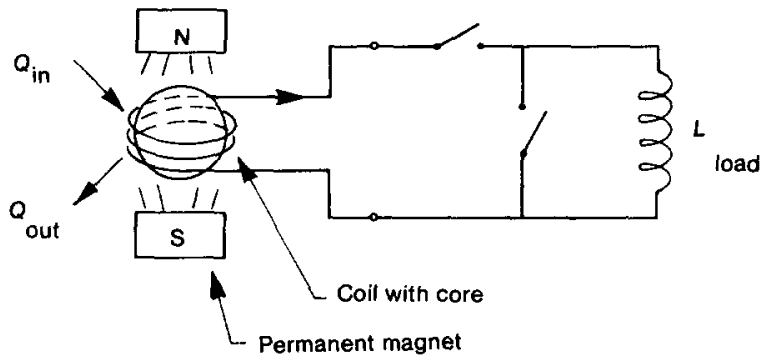

Fig. 24 Thermal magnetic heat converter drives a half wave rectifier

\section{Final remarks}

The best known types of flux pumps have been presented in the above. Nearly all of them only demonstrate the principle, and are of very little relevance to practical use. The transformer rectifier is the most promising one and therefore deserves more attention. So in the next issue, part 2 continues with the transformer rectifiers, especially the fullwave rectifier. Moreover, the theoretical behaviour of both dynamos and rectifiers is shown.

\section{References}

\section{Miscellaneous}

1 Ampère, A.M. Mem, Acad Sci Pans 6 (1823)

2 Felici, N.J. Cr Acad Sci Paris 206 (1938) 242, Cr Acad Sci Paris 206 (1938) 599, Ann Phys Paris 13 (1940) 266

3 Rose, D.J., Lidsky, L.M., Wingerson, R.C. The magnetic pump - a device for the mechanical generation of high magnetic fields, Quaterly Progess Rep., Res. Lab. of Electronics MIT (1961) 31

4 Chester, M. Thermodynamics of superconducting energy converter, J A ppl Phys 33 (1962) 643

5 Chester, P.F. Proc IEEE 111 (1964) 411

6 Wipf, S.L. The efficiency of flux pumps, Proc Int Conf Magnet Techn, Stanford (1965) 615

7 Atherton, D.L. Flux pump efficiency, Cryogenics 7 (1967) 51

8 Rosner, C.H. Progress in the application of electrically switched flux pumps, IEEE Mag-4 (1968) 403

9 Newhouse, V.L. On minimizing flux pump heat dissipation, IEEE Trans on Magnetics Mag-4 (1968) 482

10 Lubell, M.S., Efferson, E.R. Flux pumps as power supplies in comparison with alternatives, Proc 1968 Summer Study on sc devices and accelerators, BNL 50155 (C-55) (1969) 667

11 Wipf, S.L. Summary of the fourth week - ac losses, instability and flux pumps, Proc 1968 Summer Study on sc devices and accelerators, BNL 50155 (C-55) (1969) 683

12 Newhouse, V.L. Flux pumps, dynamos, and motors, Ed. R.D. Parks (Marcel Dekker, Inc. New York) Superconductivity II (1969) 1295

13 Otter, F.A. Thermomagnetic generation of power in a superconductor, US patent 3,478,230 (1969)

14 Britton, R.B. Power supply for superconducting magnet, US patent $3.521,207(1970)$

15 Huebener, R.B. Direct-current generator for superconducting circuits, US patent 3,593,110 (1971)

16 Robertson, R.W., Irey, R.K. Direct energy conversion utilizing a superconducting flux pump, Proc ICEC 4, Eindhoven (1972) 236

17 Clarke, J., Freake, S.M. Superconducting fountain effect, Phys Rev Lett 29 (1972) 588

18 Foner, S. Schwartz, B.B. Superconducting machines and devices, Plenum Press, New York (1974)

19 Cabrera, B. Generating ultra-low magnetic field regions with superconducting shields and their use with a sensitive magnet charge detector, Proc LT 14, 4 (1975) 270

20 Lefrane, G., Müller, A., Nachtrieb, K. Shielding with superconducting tubes made of niobium-Tin sinter material, Proc. ICEC 7 (1978) 719

\section{Flux compressors}

21 Rothwarf, F., Thiel, R.C. Persistent currents in hollow cylinders of Niobium-Tin Bull Amer Phys Soc 7 (1962) 189
22 Elleman, D.D., Hildebrandt, A.F., Simpkins, R., Whitmore F.C. Superconducting flux pump Bull Amer Phys Soc 7 (1962) 309

23 Hempstead, C.F., Kim, Y.B. Induced persistent currents in superconducting flux concentrators Bull Amer Phys Soc 7 (1962) 309

24 Hildebrandt, A.F., Wahlquist, H., Elleman, D.D. Configurations of superconducting shells required for near critical uniform magnetic fields $J$ App Phys 33 (1962) 1798

25 Swartz, P.S., Rosner, C.H. Characteristics and a new application of high-field superconductors $J$ Appl Phys 33 (1962) 2292

26 Hildebrandt, A.F., Elleman, D.D., Whitmore, F.C., Simkins, R. Some experimental consequences of flux conservation within multiply connected superconductors $J A$ ppl Phys 33 (1962) 2375

27 Elleman, D.D., Hildebrandt, A.F. The generation of intense magnetic fields with superconductors using induction Proc LT8, Butterworths, London (1963) 332

28 Goldsmid, H.J., Corsan, J.M. Flux compression in hard superconductors Phys Lett 10 (1964) 39

29 Atherton, D.L. Superconducting means for obtaining high magnetic fields, US patent $3,233,155$ (1966)

30 Hildebrandt, A.F., Elleman, D.D., Whitmore, F.C., Simpkins, R.A. Continuous magnetic flux pump, US patent $3,244,943$ (1966)

31 Hildebrandt, A.F., Elleman, D.D., Whitmore, F.C. Magnetic flux pump US patent 3,262,025 (1966)

32 Williams, M. Use of bulk sintered superconductors to generate high magnetic fields $J$ Sci Tech 36 (1969) 93

33 Williams, M. A mechanical flux compressor using superconducting sintered $\mathrm{Nb}_{3} \mathrm{Sn}$ tubes Cryogenics 11 (1971) 308

34 Rose-Innes, A.C. A superconducting magnetic flux compressor Cryogenics 13 (1973) 103

\section{Superconducting dc dynamos}

35 Marchand, J.F., Volger, J, Radiation induced transport of magnetic flux along a superconducting sheet, Phys Lett 2 (1962) 118

36 Volger, J., Admiraal, P.S. A dynamo for generating a persistent current in a superconducting circuit Phys Lett 2 (1962) 257

37 van Beelen, H., Amold, A.J.P.T., de Bruyn Ouboter, R., Beenakker, J.J.M., Taconis, K.W. A flux pump for the generation of high persistent currents in a superconducting foil magnet, Phys Lett 4 (1963) 310

38 Volger, J., van Suchtelen, J. Induction of heavy persistent currents, Conf on high magnetic fields, their production and their applications, Clarendon Laboratory, Univ of Oxford, July 10-12 (1963)

Volger, J. A superconducting homopolar dynamo for the production of large persistent currents and the problem of energizing a coil, Philips Technicla Rev 24 (1963) 399

Volger, J. A dunamo for generating a persistent current in a super conducting circuit Phillips Technical Rev 25 (1963) 16

39 van Beelen, H., Amold, A.J.P.T., Sypkens, H.A., de Bruyn Ouboter, R., Beenakker, J.J.M., Taconis, K.W. A 25000 Gauss, 175 amperes $\mathrm{Nb}-25 \% \mathrm{Zr}$ wire magnet fed by a flux pump Phys Lett 7 (1963) 175

40 Wipf, S.L., A superconducting direct-current generator, $A d v$ Cryog Eng Ed. K. Timmerhaus (Plenum Press NY) 9 (1964) 342

41 Anonymous, Superconducting dc generator Electr Rev (1964) 22

42 van Houwelingen, D., Admiraal, P.S., van Suchtelen, J, A superconducting dc dynamo driven by a rotary magnetic field Phys Lett 8 (1964) 310

43 Sass, A.R. Analysis of a distributed superconductive energy converter, IEEE Transactions on Aerospace 2 (1964) 822

44 Anonymous (Wipf) A miniature generator produces high current, IEEE Spectrum (1964) 198

45 Atherton, D.L. Superconducting dc generators and motors, IEEE Spectrum (1964) 67

46 Volger, J. The generation of heavy currents in superconducting circuits, $A d v$ Cryog Eng Ed. K. Timmerhaus (Plenum Press, NY) 10B (1965) 98

47 Blaisse, B.S., Kickert, O., Bots, G.J.C., Sipman, L.A. A small size superconducting dynamo powered by ac current, Phys Lett 14 (1965) 5 
van Beelen, H., Arnold, A.J.P.T., Sypkens, H.A., van Braam, Houckgeest, J.P., de Bruyn Ouboter, R. Beenakker, J.J.M., Taconis, K.W. Flux pumps and superconducting solenoids, Physica 31 (1965) 413

49 Wipf, S.L. Flux pumps as power supplies for superconducting coils, Proc Int Symp Magnet Techn. Stanford Un., Palo Alto (1965) 615

50 van Suchtelen, J., Volger, J., van Houwelingen, D. The principles and performance of a superconducting dynamo Cryogenics 5 (1965) 256

51 Voigt, H. Eine Untersuchung der Vorgänge in supraleitenden Flusspumpen, $Z$. Naturforchung 21a (1966) 510

52 Berlincourt, T.G. Method and apparatus for magnetic flux accumulation and current generation, US patent $3,277,322$ (1966)

53 Hoag, E.D. Superconductive device, US patent 3,292,021 (1966)

54 Weber, R. Messungen zur Wirkungsweise supraleitende Flusspumpen, $Z F$ angew Physik 22 (1967) 449

55 Volger, J. Device for producing a current, US patent $3,336,489$ (1967)

56 Atherton, D.L. Method and means for obtaining high magnetic fields, US patent 3,336,509 (1967)

57 van Beelen, H., van Braam Houchgeest, J.P., de Bruyn Outober, R., Taconis, K.W. Remarks on a moving-flux experiment in superconducting sheets, Physica 36 (1967) 107

58 McFarlane, I.D. A flux pump with only frictional losses, Cryogenics 7 (1967) 267

59 van Beelen, H. Fluxmotion in superconductors, Thesis, Leiden University, the Netherlands (1967)

60 Lubell, M.S., Wipf, S.L. A cabled-wire magnet powered by a flux pump, Adv Cryog Eng 13 (1968) 150. Proc ICEC 1 (1967) 137

61 Atherton, D.L. High efficiency superconducting homopolar dc generators, J A ppl Phys 39 (1968) 2639

62 van Houwelingen, D., Volger, J. The superconductingdynamo properties and applications, Phillips Res Repts 23 (1968) 249

63 Wipf, S.L. Flux pumps with moving magnetic fields, IEEE MAG 4 (1968) 493

64 Pearl, J. Motors and generators employing superconductors, US patent $3,402,307$ (1968)

65 Atherton, D.L. Practical aspects of homopolar superconducting dc generators, Cryogenic Eng News (1968) 30

66 Hulm, J.K. Superconductors in technology, Ed. M.H Cohen, University of Chicago Press (1968)

67 Wipf, S.L. The case for flux pumps and some of their problems, Proc 1968 Summer Study on sc devices and accelerators, B NL 50155 (C-55) (1969) 632

68 van Beelen, H., de Langen, M., Kerkdijk, C.B.W. Comments on the efficiency of flux pumping into superconducting circuits, Physica 42 (1969) 265

69 Eder, F.X., Voigt, H. Superconductive generators, US patent $3,478,232$ (1969)

70 Voigt, H. Superconducting generator, US patent $3,519,892$ (1970)

71 Appleton, A.D., Flux pumps, Conf Low Temp and Elec Power, London 1969 (1970) 207

72 McFarlane, I.D. Super conducting dynamoelectric machine, US patent $3,560,773$ (1971)

73 Lihl, F., Weber, R. Zur Wirkungweise supraleitender Flusspumpen, Z agnew Physik 31 (1971) 250

Kawabe, U. Flux pump, US patent 3,602,854 (1971)

75 Cherry, W.H. Homopolar apparatus which requires no moving parts for producing direct current, US patent $3,611,113$ (1971)

76 Bergmann, W.H. Method and means for charging or discharging superconducting windings, US patent $3,667,029$ (1972)

see also Bergmann, W.H. Proposal for a flux pump utilizing the inverse Ettingshausen effect in hard type II superconductors in the mixed state, Proc 1968 Summer Study on sc devices and acclerators B NL 50155 (C-55) (1969) 681

77 Wipf, S.L. A $50 \mathrm{kA}$ flux pump for the superconducting transmission line test bed, Los Alamos Sci Lab., Informal Report LA-6953-MS (1974, revised 1978)

78 Glebov, I.A. Superconducting magnetic systems and electrical machines IEEE MAG-11 2 (1975) 657

79 Buchhold, T.A. Superconductive machinery Ed. V.L. Newhouse, Academic Press NY (1975) 511
80 Mawardi, O.K., Muelder, S.A., Michelotti, R.A. Brushles superconducting alternators, IEEE MAG-13 (1977) 780

81 Arsala, N.K., Louzada, E.G., van Beelen, H. The penetration of a local magnetic field through large sheets of type-1 superconductors, Physica 93B (1978) 75

82 Mawardi, O.K., Muelder, S.A. Theory and design of a brushless superconducting alternator, Rep EPRI El-479 (1978)

83 Rabinowitz, M., Rodenbaugh, I.J. Superconducting hybrid magnetic flux pump, US patent 4,096,403 (1978)

84 Mawardi, O.K., Gattozzi, A., Chung, H. Operational characteristics of a flux pump IEEE MAG-15 (1979) 828

\section{Transformer rectifier flux pumps}

85 Mendelsohn, K. Production of high magnetic fields at low temperatures Nature, London 132 (1933) 602

85b Ericsson, E.A., Jorgensen, A.O., Overby, S.L. Rectifier and converter using superconduction US patent 2.666 .884 (1954)

86 Olsen, J.L. Einr supraleitender Gleichrichter und Verstärker $Z$ Angew Math Phys IXa (1958) 293

87 Olsen, J.L. Superconducting rectifier and amplifier, $R e v$ Scie Instr 29 (1958) 537

88 McFerran, J.B. The direct current transformer, Adv Cryog Eng 6 (1961) 136

89 Purcell, J.R., Payne, E.G. Superconducting rectifiers, $A d v$ Cryog Eng 6 (1961) 149

90 Laquer, H.L. Powering high current superconducting solenoids by accumulation of flux, Post deadline paper RA 15 Washington Meeting, American Phys Soc (1962)

91 Laquer, H.L. An electrical flux pump for powering superconducting magnet coils, Cryogenics 3 (1963) 27

92 Laquer, H.L. Flux trapping and flux pumping with solenoida superconductors, Proc 11 th Int Conf Refrigeration (1963) 207

93 Lempstead, C.F., Kim, Y.B., Strand, A.R. Inductive behaviour of superconducting magnets, J Appl Phys 34 (1963) 3226

94 Buchhold, T. Cryogenic flux pump switches high currents Electronics (1964) 61

95 Buchhold, T. Superconductive power supply and its application for electrical flux pumping, Cryogenics 4 (1964) 212

96 Anonymous (Buchhold), IEEE Spectrum (1964) 196

97 Laquer, H.L. Incremental electrical method and apparatus for energizing high current superconducting electromagnets, US patent $3,150,291$ (1964)

98 Watt, D.A. A superconducting transformer and charging circuit for a high field magnet, AERE-M 1397, Harwell (1964)

99 Laquer, H.L., Carroll, K.J., Hammel, E.F. An automatic superconducting flux pump, Phys Lett 21(1966) 397

100 Laquer, H.L., Carroll, K.J., Hammel, E.F. An automatic superconducting flux pump, Supplèment au Bulletin de l'Institut International du Froid, Commission 1, Boulder (1966) 539

101 Prior, A.C. Superconductive circuit arrangements, US patent $3,271,628(1966)$

102 T. Buchhold, Super conductive rectification and its use for flux pumping, bull. II R, Commission 1 (1966) 529

103 Arnold, R.T. Super conductive flux magnifier, US patent 3,320,522 (1967)

104 Buchhold, T. Cryogenic pumped rectifier systems, US patent 3,356,924 (1967)

105 Fasel, R., Olsen, J.L. A superconducting bridge rectifier, 12e Congress Int. du Froid, Rapport 1-12, Madrid 1 (1967) 149

106 Minet, R. Accumulation de courants continus intenses avec pompe de flux et transformateur supraconducteurs, $C R$ Acad Sc Paris, t 266, Serie B (1968) 1561

107 Rhodenizer, R.L. Design principle and characteristics of the G.E. flux pump, Proc 1968 Summer study on superconducting devices and accelerators, Brookhaven National Laboratory (BNL 50155) Part II (1968) 654

108 Laquer, H.L. Flux pump work at Los Alamos, Proc 1968 Summer Study on superconducting devices and accelerators, Brookhaven National Laboratory (BNL 50155) Part II (1968) 673

109 Britton, R.B. $60 \mathrm{~Hz}$ flux pumps, Proc 1968 Summer Study on superconducting devices and accelerators, Brookhaven National Laboratory (BNL 50155) Part II (1968) 679 
110 Laquer, H.L., Carroll, K.J., Hammel, E.F. A utomatic superconducting pump, US patent $3,414,777$ (1968)

111 Faseil, R., Olsen, J.L. Superconducting rectifiers, Int Inst of Refrigeration Low Temperatures and Electric Power, Conf London 1969, (Pergamon Press, NY 1970) 303

112 Spiel, D.E., Boom, R.W. Super conductive energy storage with a flux pump, Int Inst of Refrigeration Low Temperatures and Electric Power, Conf London 1969' (Pergamon Press, NY 1970) 433

113 Ferrier, M. Problems associated with the manufacture of industrial superconducting rectifiers, Proc ICEC 3 Berlin (1970) 438

114 Britton, R.B. Flux pumps for use at $60 \mathrm{~Hz}$, IEEE Trans Nucl Sci NS-18, 3 (1971) 681

115 Britton, R.B., Robins, K.E. Multiaction flux pump, US patent 3,568,002 (1971)

116 Britton, R.B. Proc 1971 Particle Accelerator Conferenœ, Chicago II BNL 1565

117 Britton, R.B., Abbatiello, F.J., Robins, K.E. Flux pumps and ac superconducting components, 4th Int Conf on Magnet Technology, Brookhaven BNL 17225 (1972) 703

118 Fasel, R. Theoretische und experimentelle Untersuchungen stromgesteuerter supraleitender Schaltelementen mit Richtwirkung und ihre Anwendung in superleidenden Stromgleichrichtern, Thesis E.T.H. Zurch 1973 (Diss. Nr. 4898)

119 Caroll, K.J. Behaviour of a flux pump using an automatic superconducting switch, Cryogenics 13(1973) 353 An investigation of reliable, high current flux pumps, Rep. 1680-2, Un. of Oklahoma Res Inst (1971)

120 Vilbikaitis, R.J. Design and development of 1000-Ampere cryotrons for use in a superconducting flux pump, Master $\mathrm{Sc}$ Thesis (Queen's University Canada, 1974)
121 Ichikawa, $\mathbf{H}$, Utsunomiya, $\mathbf{S}$. Method and apparatus for charging a superconductive coil, US patent $3,848,162$ (1974)

122 Atherton, D.L., Vilbikaitis, R.J. 1000 A cryotrons for super conducting-magnet flux pumps, Rev Sci Inst 45 (1974) 1520

123 Homer, G.J., Houzego, P.J., Scott, C.A., Wilson, M.N. A thermally switched flux pump, IEEE Trans on Magnetics MAG-11 (1975) 576

124 Droege, T.F., Purcell, J.R., Wang, S.T. A slow cycling flux pump using digital control, IEEE Trans on Magnetics MAG-11 (1975) 580

125 Bernat, T.P., Blair, D.G., Hamilton, W.O. Automated flux pump for energizing high current superconducting loads, Rev Sci Instr 46 (1975) 582

126 Bernard, S.P. Rectifier flux pump power supplies for high current superconducting magnets, Master Sci Thesis (Queen's University Canada, 1976)

127 Gray, K.E., Huebener, R.P., Chen, W.K., Fowler, D.E. Superconducting rectifier development, EPRI report TP 245 Palo Alto, Calif. (1976), US Department of Commerce PB-257533

128 Bernard, S.P., Atherton, D.L. Performance analysis of transformer-rectifier flux pumps, Rev Sci Instr 48 (1977) 1245

129 Bemard, S.P., Atherton, D.L. High-efficiency flux pump power supply using inductive current transfer, Rev Sci Instr 48 (1977) 1250

130 Akerlof, C., Droege, T., Visser, A., Britton, R. Development of a high power flux pump, Progress Report Um HE 78-27 Fermi Nat Lab (1978)

131 Dronov, A.S., Ignativ, V.Y., Misyulin, A.V. IEEE Trans on Magnetics MAG-15 (1979) 836

132 Atherton, D.L., Davies, R. Transformer-rectifier flux pump using inductive current transfer and thermally controlled $\mathrm{NB}_{3}$ Sn cryotrons, Rev Sci Instr 50 (1979) 1245 